University of Nebraska - Lincoln

DigitalCommons@University of Nebraska - Lincoln

Faculty Publications, Department of Psychology

Psychology, Department of

6-1-1985

Pubertal Timing and Grade Effects on Adjustment

Anne C. Petersen

Pennsylvania State University, annepete@umich.edu

Lisa J. Crockett

University of Nebraska-Lincoln, ecrockett1@unl.edu

Follow this and additional works at: https://digitalcommons.unl.edu/psychfacpub

Part of the Psychiatry and Psychology Commons

Petersen, Anne C. and Crockett, Lisa J., "Pubertal Timing and Grade Effects on Adjustment" (1985).

Faculty Publications, Department of Psychology. 234.

https://digitalcommons.unl.edu/psychfacpub/234

This Article is brought to you for free and open access by the Psychology, Department of at DigitalCommons@University of Nebraska - Lincoln. It has been accepted for inclusion in Faculty Publications, Department of Psychology by an authorized administrator of DigitalCommons@University of Nebraska - Lincoln. 


\title{
Pubertal Timing and Grade Effects on Adjustment
}

\author{
Anne C. Petersen ${ }^{1}$ and Lisa Crockett $^{2}$
}

\begin{abstract}
Effects on adjustment of biological maturation and social timing were compared using data from a longitudinal sample of 335 young adolescents, who were followed from the sixth through eighth grades. Biological maturation was estimated from the relative timing of the adolescent growth spurt. Social timing was assessed by grade in school. Five adjustment constructs were examined: school achievement (course grades in five subjects), family relations (a 17-item scale), peer relations (a 10item scale), body image (an 11-item scale), impulse control (an 8-item scale), and psychopathology (an 11-item emotional tone scale and an 11-item general psychopathology scale). All but one adjustment construct showed grade effects, but only three of the six constructs showed pubertal timing effects. There were no grade by pubertal timing effects. Although there were gender differences for some of the adjustment constructs, there were no gender by pubertal timing effects. The results are discussed in terms of the life-span developmental perspective.
\end{abstract}

\section{INTRODUCTION}

It is strongly believed that adjustment during the adolescent years is affected by the timing of pubertal changes. Previously, we (Petersen and Taylor,

${ }^{1}$ Professor of Human Development and Head, Department of Individual and Family Studies, The Pennsylvania State University. Received Ph.D. from the University of Chicago in 1973. Research interest is biopsychosocial development in early adolescence, with a focus on sex differences.

${ }^{2}$ Post-doctoral Fellow, Department of Mental Hygiene, School of Public Health, Johns Hopkins University. Received Ph.D. from the University of Chicago. Research interests are social development, biosocial interactions in early adolescence, and sex differences. 
1980) identified two hypotheses concerning pubertal timing effects: (1) a deviance hypothesis and (2) a stage termination hypothesis.

According to the deviance hypothesis, early versus late maturers differ in adjustment because of their status relative to the rest of the peer group. Early or late maturation places the adolescent in a socially "deviant" category, which may confer either social advantages or disadvantages. Differential psychosocial effects are thought to be a function of the social stimulus value of early versus late maturation. The timing of maturation is hypothesized to have an impact because of socially shared beliefs about when major life events should occur (Neugarten, 1979). The expectations of others and oneself influence perceptions of being on time or off time (Neugarten and Datan, 1973) and affect the adolescent's social prestige, social adaptation, and self-concept. Because girls who mature early are much earlier than the majority of their peers, and boys who mature late are much later, these two groups are likely to be at risk for difficulties associated with being socially deviant.

According to the stage termination hypothesis, differences between early and late maturers may be a function of the amount of time available for continued psychosocial development prior to the onset of puberty. It is assumed that puberty marks the end of middle childhood and the beginning of early adolescence. This perspective, articulated by Peskin and Livson (1972; Peskin, 1973), posits that early maturation interrupts the acquisition and consolidation of adaptive skills that characterize the middle childhood years. According to this hypothesis, girls, and early maturers in general, would be at greater risk for adjustment problems. Although Peskin and Livson note that the additional time available to early maturers during adolescence may compensate for the earlier interruption, one would nevertheless expect early adolescence to be more difficult for young people in this group because of the need to deal with new feelings and expectations at a time when they have not completed the tasks of the previous phase.

Research has provided a mixed pattern of support for the deviance hypothesis. The state termination hypothesis has only been examined by one investigator (Peskin, 1967, 1973). On the basis of the existing data on boys, one might conclude that the deviance hypothesis is supported for social variables, given that later maturation seems to be associated with social disadvantage (Clausen, 1975; Jones, 1965; Jones and Bayley, 1950; Mussen and Jones, 1957; Savin-Williams, 1979), while the stage termination hypothesis is supported for mood variables (Peskin, 1967). For girls, contradictory results are obtained on social variables (e.g., Faust, 1960; Clausen, 1975; Jones and Mussen, 1958; Simmons et al., 1983; Stolz and Stolz, 1944), while the stage termination hypothesis is again supported for mood variables (Peskin, 1973).

None of this research has compared pubertal timing effects with other timing influences. Proponents of the life-span perspective in development (e.g., Baltes and Reese, 1984) have delineated three factors that may influence the course of development: age-graded, history-graded, and nonnormative influences. Among age-graded influences, they include all normative age-related factors. As we have noted (Petersen, in press b), several kinds of "age-graded" factors may be identified, including (1) chronological age, which indexes years of life and presumably reflects amount of life experience; (2) biological age, with pubertal age being most relevant in the present discussion; (3) cognitive age, which may refer to either intelligence (commonly indexed by amount of intellectual competence relative to chronological age) or cognitive stage in the Piagetian sense (Inhelder and Piaget, 1958; specifically whether one exhibits the capacity for formal operational thought); and (4) grade in school, which in our society often defines what one has learned, both academically (based on school curriculum) and socially, in terms of social norms and expectations that characterize the cohort of peers at each grade level.

In the research presented here, we assessed all four dimensions of agegraded influences but will focus primarily on biological age and grade in school. In our sample there is little difference between chronological age and grade in school; the standard deviation of age within grade cohort is only three months for both boys and girls (Richardson, et al., 1984). Cognitive age will be examined in future analyses.

The design for the analysis presented here includes pubertal timing and grade as independent variables, with grade being a repeated factor (grades 6 , 7 , and 8). In addition, we included gender as an independent variable because of evidence that boys and girls diverge in development during early adolescence (Maccoby and Jacklin, 1974; Petersen and Taylor, 1980). All interaction terms were also included.

\section{METHOD}

\section{Design and Sample}

A cohort-sequential longitudinal design (Baltes, 1968; Schaie, 1965) was utilized for this research. The focus on investigating developmental process over the early adolescent years required a longitudinal design (rather than a 
cross-sectional one); two successive birth cohorts were sampled to permit the replication of results. ${ }^{3}$

The 335 participating young adolescents and their families were selected randomly from the sixth-grade classes of two suburban school districts in the Midwest. There was an initial refusal or lack-of-response rate of $20 \%$ on the part of selected subjects, with no variations by cohort or school district. Participants were followed for three years, through the adolescents' eighth-grade year. By the end of this phase of the study, $4 \%$ of the sample had moved and $6 \%$ had dropped out. There is no evidence that the remaining sample differs from the original sample in any way. Furthermore, a comparison between the self-image scores of the entire population of sixth- and eighth-graders and those of our subjects revealed no significant differences.

The assessment design involved group testing and individual interviews with the adolescents each fall and spring of the school year. Parents were interviewed and tested twice during the study. The primary battery of assessments is described in Petersen (1984). Only those used in the present analysis will be described here.

\section{Measures}

Pubertal Timing. We used annual height data to estimate age at peak height velocity using a method developed by Bock et al. (1973; Thissen, et al., 1976). This maximum likelihood estimation procedure begins with Bayesian priors based on data from the major growth studies in this country. Analysis of longitudinal data from these studies has verified the validity of a triple logistic function representing growth in stature from birth (actually conception) to maturity. Although nine parameters are estimated, only one - age at peak height velocity during the adolescent growth spurt - is of interest in the present analysis.

The estimates of age at peak height velocity (i.e., age at which growth is fastest) were based on repeated measures of height over the three years of the study. However, the nature of the height data differed for the two school districts involved. In one school district, height was measured annually from kindergarten through eighth grade by the school nurse; these data on height, obtained directly from school records, were used to estimate age at peak height velocity. In the other district, objective data on height were not available; therefore we used the adolescents' self-reports of height to make the estimates. The self-reports were obtained from the adolescents in both school districts as part of the semi-annual interviews. Thus, reported and objective values could be compared directly in one of the districts; comparisons indicated that the self-report data were valid

${ }^{3}$ Cohorts are often used to examine cohort-related or historical change. In this research the two cohorts differed by only one year, so there was no reason to expect such effects. (median $r=0.94$ ) (Crockett, et al., 1985). Moreover, comparisons between the estimates based on objective data and those based on self-reported data indicated a substantial amount of overlap. Finally, when estimates from the two districts were compared (one set based on objective data, the other on self-reports), no significant differences emerged. Given these findings, we combined the estimates from both districts in subsequent analyses.

To derive pubertal timing categories, the distribution of scores representing estimated age at peak height velocity was trichotomized, with the lower third being classified as "early," the middle third as "on time," and the upper third as "late" maturers. This procedure was carried out separately for boys and girls in order to take into account the gender difference in the age at which puberty begins. (In other samples, the age at peak height velocity is 11 years for girls and 13 years for boys, with the standard deviation usually around one year; Bock et al., 1973.)

Table I shows the average ages at peak height velocity for each group. As expected, the means differ by about one year for each timing group. Furthermore, the group standard deviations are smaller than the overall standard deviation, around 0.5 for the extreme groups and 0.11 and 0.19 for girls and boys, respectively, in the middle group. Age at menarche for girls, based on information from the girls and from their mothers, also reveals predictable variation by timing group. Finally, age at menarche follows age at peak height velocity by about one to one-and-a-half years for each category, a difference seen with other data as well (e.g., Petersen, 1979). All of these results support the validity of the timing groups.

The validity of the pubertal timing classification may also be seen in the means and standard deviations of the young adolescents' scores on the Pubertal Development Scale (PDS; Petersen et al., 1984a) in Table I. The PDS is a self-report instrument on which adolscents report their level of development for five indices of pubertal growth. For girls, the items include breast development, attainment of menarche, pubic hair development, extent of stature completed, and skin change. The scale for boys includes the last three girls' items plus facial hair growth and voice change. In both sexes, PDS scores typically decrease across the timing categories, with occasional variations because of small $n s$ or sampling variation.

Adjustment. The outcome of interest in the present study is the adjustment, or mental health, of the young adolescents. Adjustment is considered in several domains: school, family, peer group, and as perceived by the self. Several aspects of self-perceptions seemed especially relevant here: body image, impulse control, and psychopathology. Because our goal was to compare effects of pubertal timing with grade effects, only measures obtained at least annually were included. 


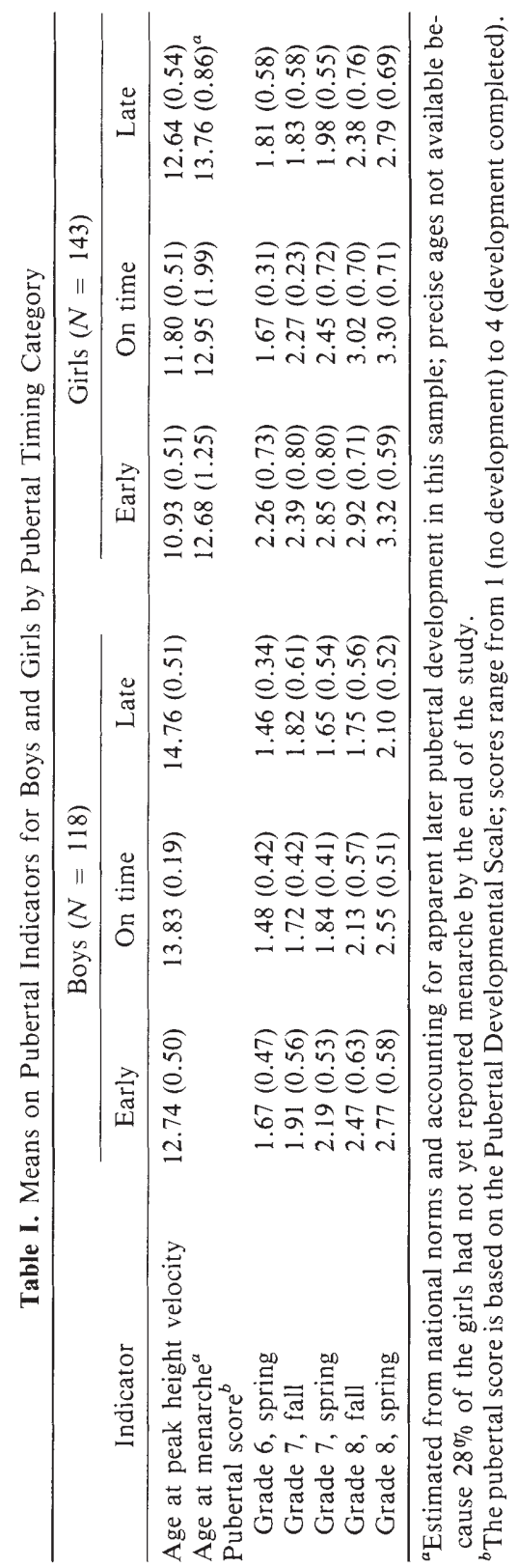

In the present study, adjustment in school was assessed by the final grades obtained each year in each of five basic courses (language arts, literature, mathematics, social studies, science). These data were obtained from school records. Letter grades (which included + and - ) were transformed into numerical scores on an 11-point scale with 0 used for "F" and 11 used for "A".

Family functioning was assessed in these analyses by the Family Relations scale of the Self-image Questionnaire for Young Adolescents (SIQYA; Petersen, et al., 19840), These self-perceptions of the family relationship are based on the average of 17 items which yields a score in the metric of the response scale. Responses to each statement are made on a 6-point Likert scale. The final score can range from 1 to 6 , where 6 represents the most positive self-image. The interitem consistency (alpha coefficient) of this scale, based on a norming sample, is given in Table II (from Petersen et al., 1984b).

Peer relationships were measured with the Peer Relations scale of the SIQYA. This scale has 10 items and is identical to the Family Relations scale in terms of its properties. The alpha coefficients for this scale are shown in Table II.

Three aspects of self-image are considered here: Body Image, Impulse Control, and Psychopathology, the latter assessed by Emotional Tone and Psychopathology, all scales on the SIQYA. Body Image includes 11 items, Impulse Control includes 8 items. Emotional Tone includes 11 items, and Psychopathology includes 11 items. The alpha coefficients for these scales are also shown in Table II.

\section{RESULTS}

Analyses of variance (multivariate in some cases) with the factors gender, pubertal timing, and grade (a repeated measures factor) were used to assess the effects of pubertal timing and grade. Polynomial contrasts (linear and qua-

Table II. Reliability of SIQYA Subscales for Boys and Girls

\begin{tabular}{lcc}
\hline \multicolumn{1}{c}{ Subscale } & Boys & Girls \\
\hline Impulse Control & 0.72 & 0.76 \\
Emotional Tone & 0.81 & 0.85 \\
Body Image & 0.81 & 0.77 \\
Peer Relations & 0.85 & 0.81 \\
Family Relations & 0.88 & 0.88 \\
Psychopathology & 0.79 & 0.80 \\
\hline
\end{tabular}

${ }^{a}$ Cronbach's coefficient alpha was used to assess subscale reliability. These data are based on a validity sample of 343 eighth-grade students in the retest control group for the study. 
dratic) were used for within-factor a priori comparisons of levels of pubertal timing and grade. Separate analyses were conducted for each construct.

The results of these analyses are summarized in Table III. Because the results are complex, they are discussed by type of effect. Between-subjects effects are discussed first and within-subjects effects (i.e., those involving grade in school) are described second.

\section{Gender}

Boys and girls differed significantly on two constructs: School Achievement and Body Image. Girls had significantly higher average grades than boys (multivariate $F=4.92, p<0.001$ ) in language arts, literature, and social studies. Boys' body image was significantly higher than that of girls $(F$ $=11.68, p<0.001)$.

\section{Pubertal Timing}

Pubertal timing had a significant effect on school achievement (multivariate $F=1.97, p<0.05)$, impulse control $(\mathrm{F}=3.42, p<0.05)$, and psychopathology (multivariate $F=2.70, p<0.05$ ). With respect to school achievement, only course grades in literature showed a significant effect, with early maturers receiving higher grades than on-time and late maturers. In contrast, late maturers reported more impulse control than early or on-time maturers Of the two scales assessing the Psychopathology constructs, only the Psychopathology subscale of the SIQYA showed a significant univariate effect. Late maturers reported the least psychopathology, early maturers the most, with on-time maturers reporting an intermediate level.

\section{Gender by Pubertal Timing}

There were no significant interactions between gender and pubertal timing; however, the pubertal timing categorization was done within gender. Still, the absence of interaction effects suggests that the importance of pubertal timing relative to others of one's gender is similar for boys and girls.

\section{Grade}

Grade in school had a significant effect on all adjustment constructs measured, with the exception of Impulse Control. For School Achievement, grades

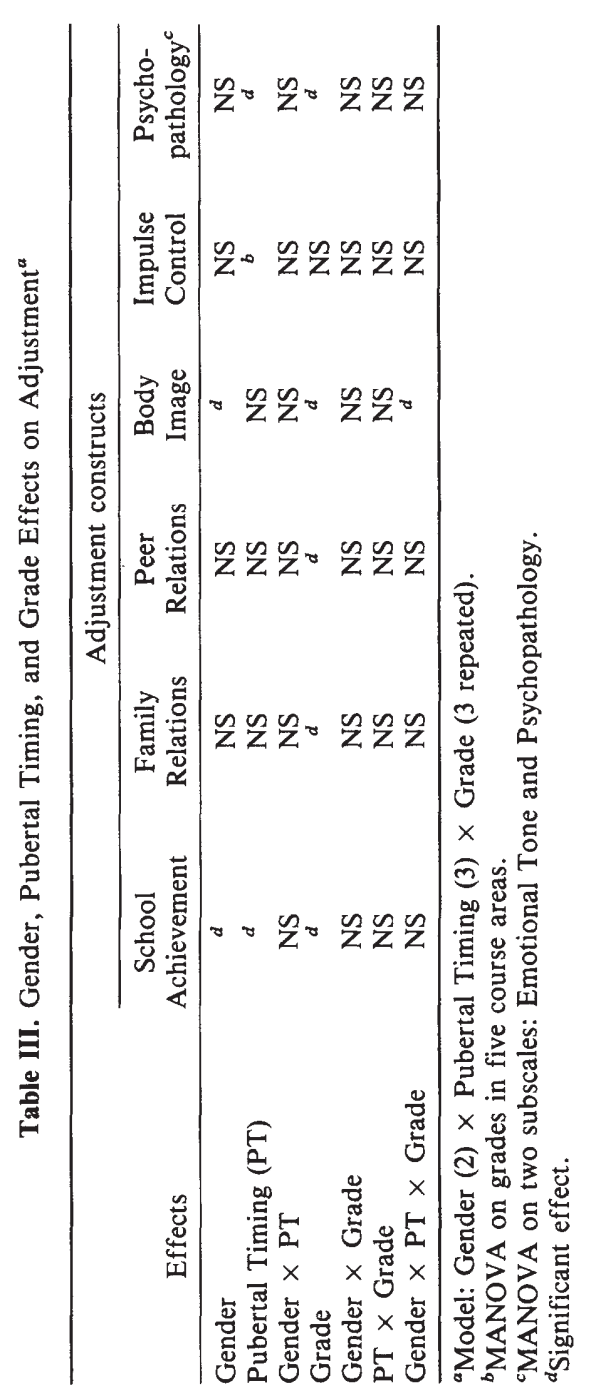


in four of the five subject areas declined between sixth and eighth grade (multivariate $F=15.09, p<0.0001$ ), with the major drop occurring between sixth and seventh grade. This pattern of differences was found for language arts, math, science, and social studies; only literature grades did not differ significantly by grade in school. Perceptions of family relations $(F=3.49, p<$ 0.05 ) showed a slight decline over the same period, although the decline occurred between seventh and eighth grade. In contrast, perceptions of peer relations improved $(F=7.53, p<0.001)$, especially between sixth and seventh grade. Body image scores generally declined with grade level $(F=7.69$, $p<0.001)$; however, significant interactions with gender and pubertal timing modified this general effect. Finally, for psychopathology (multivariate $F$ $=9.36, p<.0001$ ), only emotional tone varied significantly with grade level. Emotional tone increased over the three years, especially between sixth and seventh grade.

\section{Gender by Grade}

There were no significant gender by grade interactions. This result suggests that the grade-related patterns of change were similar for boys and girls.

\section{Pubertal Timing by Grade}

There were no significant interactions between the two effects of primary interest: pubertal timing and grade. This suggests that the pattern of change over time was similar for early, on-time, and late maturers, and the relative ranking of the three groups in terms of the adjustment constructs considered in these analyses did not vary across the three grades.

\section{Gender by Pubertal Timing by Grade}

A significant three-way interaction emerged for only one construct: Body Image $(F=3.06, p<0.05)$. Inspection of the means indicates that for boys, average body image scores were stable across the three grade levels among early maturers, while scores dropped for both on-time and late maturers between sixth and seventh grade. This decline was particularly steep among late maturers, but body image in this group increased again by eighth grade. The differing developmental patterns produced a convergence in scores: In eighth grade, average body image scores differed less across the three pubertal timing groups than in previous grades, with the late group being highest, the early group second, and the on-time group lowest.
For girls, the pattern was quite different. Body image scores of early maturers, although relatively high to begin with, declined steadily over the three years. Scores for late maturers dropped somewhat between seventh and eighth grade, and scores for on-time girls remained stable, with the result that early maturing girls ended up with somewhat lower body image scores than the others.

This interaction is shown in Figure 1, which more clearly reveals two salient aspects: (1) Boys in general have higher body image than girls, and (2) the interaction effect is probably due to the striking dip in body image reported by late maturing boys in seventh grade. This dip prompts speculation that the late maturing boys may have become alarmed at their lack of development in seventh grade, only to be reassured again in eighth grade when most of them were likely to experience some pubertal growth.

\section{Summary}

Gender effects were seen with two of the six constructs: Girls tended to receive higher course grades, while boys reported more positive body image. Pubertal timing had a significant effect on three constructs: course grades (early maturers higher in literature), impulse control (more among late maturers), and psychopathology (more among early maturers). By comparison, significant change related to grade in school was found on all constructs except Impulse Control. The main effects for grade level on achievement, family re-

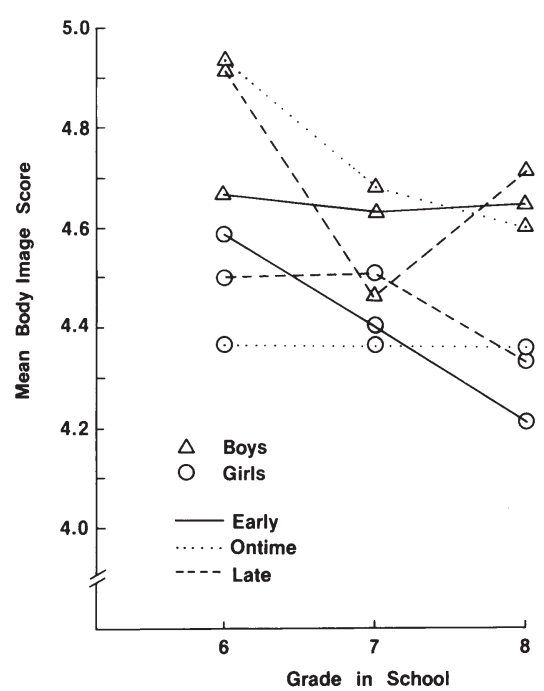

Fig. 1. Interaction effect on body image of grade in school, timing of pubertal maturation, and gender. 
lations, peer relations, and psychopathology can be interpreted directly. (The effect on body image requires interpretation of an interaction effect.) Briefly, course grades and family relations declined, but peer relations and emotional tone increased over the early adolescent years. Only one interaction effect emerged: a three-way interaction on body image. Figure 1 suggests that the effect is due primarily to a dip in reported body image exhibited by late maturing boys in seventh grade.

\section{DISCUSSION}

The aim of this paper was to examine the effects of pubertal timing on adjustment, particularly relative to another important timing dimension: grade in school. The aspects of adjustment examined were those likely to be affected at this age. Our intention was to explore the possibility that multiple timing factors may influence adjustment during early adolescence and that biological age (pubertal timing) may not be the sole or even the most important factor affecting young people during this phase of development.

Pubertal timing effects were seen with school achievement (in particular, with early maturers receiving higher literature grades), impulse control (more among late maturers), and psychopathology (more among early maturers). The literature effect is perhaps not worthy of a post hoc explanation. The other two effects suggest that early maturers may have more difficulty on at least two measures of adjustment. This finding is consistent with both pubertal timing hypotheses posed earlier, at least for girls, although it probably fits best with previous research examining the stage termination hypothesis. Early maturing girls may be at risk for both reasons: social deviance and less time to consolidate middle childhood tasks.

It is surprising that there were no effects of pubertal timing on body image, the construct that frequently shows associations with pubertal status in our data (e.g., Crockett and Petersen, in press; Petersen, in press a; TobinRichards et al., 1983) and in data from other studies (e.g., Simmons et al., 1983). There was a three-way interaction but this appeared to be due primarily to the dip in body image at seventh grade among late maturing boys. Early maturing girls and on-time boys seemed to show steady declines over early adolescence, while on-time girls and early maturing boys showed little change over this period. Although some of these patterns prompt post hoc interpretations, others are not so easy to explain.

We note that the effects of pubertal timing observed in these analyses were more pervasive than the effects of pubertal status (one's degree of puber- tal development at a single point in time) examined in other analyses. In addition, pubertal status was clearly associated with body image (e.g., satisfaction with one's weight and one's appearance) in those analyses (e.g., Crockett and Petersen, in press; Petersen, in press a; Tobin-Richards et al., 1983). In contrast, pubertal timing was not related to body image in the present analyses.

Grade effects were apparent with school achievement, family relations, peer relations, body image, and psychopathology. They were not seen with impulse control, although we might have hypothesized that young adolescents would show grade-related change on this dimension. The grade effects do not conform to a single developmental pattern. School achievement and family relations declined, while peer relations and emotional tone increased. The declines in school and family functioning would probably accord well with the experience of most parents and teachers of young adolescents. Yet other data suggest that glib interpretations of these results are inappropriate (see Kavrell and Petersen, 1984; Richardson et al., 1984; Schulenberg et al., 1984). Furthermore, the increases in peer relations and emotional tone are somewhat surprising and, similarly, should probably not be interpreted as reflecting a simple or unitary developmental process (see Abramowitz et al., 1984; Crockett et al., 1984).

The pattern of results emerging from our analyses suggests that the belief in pubertal development as the primary influence on adjustment must be modified. While effects of pubertal timing emerged for three aspects of adjustment (school achievement, impulse control, and psychopathology), effects of grade level were found for all aspects of adjustment except impulse control. In other words, when pubertal timing effects were tested simultaneously, grade in school influenced more aspects of adjustment than did pubertal timing; grade in school proved the more important factor. This general conclusion is in keeping with findings from other studies suggesting that pubertal effects are specific rather than global (e.g., Simmons et al., 1983).

The primacy of grade-in-school effects in this study raises important theoretical issues. First, it is important to consider what "grade in school" indexes. In our sample, in which grade level was largely confounded with age, one thing grade in school could be indexing is amount of life experience, which increases with age (Petersen, in press b). A second, and more theoretically interesting possibility, however, is that grade in school also indexes a set of norms characteristic of young people at a particular grade level. These norms, reflecting in part the expectations of the broader society concerning behavior at a particular grade level as well as the opportunities and limitations imposed on young people by school policies, are also shaped by the young people making up the particular grade cohort. At a junior high school, the sev- 
enth-graders may have a specific identity distinct from that of the eighth-graders, in part because of the unique prior and current experiences of the cohort Somewhat different behavioral norms may prevail in the two grade cohorts, differences that may be tapped by the variable grade in school.

The possibility of grade cohort effects makes sense when one considers that many activities in our society are organized by grade rather than by other timing variables. For example, when one can play on athletic teams and the teams for which one is eligible are typically determined by grade in school. Even the few rites of passage remaining in this culture, such as the Bar or Bat Mitzvah, are typically identified with a school grade (usually seventh). In contrast, it is difficult to think of a single activity or opportunity tied to pubertal status or timing. This is not to say that pubertal status and timing are without effects; rather, they have little explicit function in our current society. This contrasts with pre-industrial societies in which adult roles and status are conferred upon menarcheal girls for example (Paige, 1983).

What we have learned is the importance of considering more than one measure of developmental timing in research with this age group. It has become increasingly common to hear that biological timing is the most relevant at this age. The present results qualify this inference: Both biological timing and social timing are important. If chronological age had not been so confounded with grade in our sample, we also might have detected variance due to that factor.

The life-span developmental perspective appears to be useful for understanding phenomena at early adolescence. We suggest, however, that the notion of age-graded influences be expanded to include biological, social and age-related timing effects. There are other points in the life span when biological time is likely to be potent - examples salient for women include menopause and the mid-thirties end of the "safe" period for first birth. We would do well to consider the biological dimension of development in our research, along with the more traditional timing measures of age and attainment of key social statuses (e.g., parenthood).

\section{ACKNOWLEDGMENTS}

We gratefully acknowledge the work of the entire staff of the Early Adolescence Study, as well as the contributions of the young adolescents who participated in the research. This research was supported by grant $\mathrm{MH}$ 30252/38142 to A. Petersen.

\section{REFERENCES}

Abramowitz, R. H., Petersen, A. C., and Schulenberg, J. E. (1984). Changes in self-image during early adolescence. In Offer, D., Ostrov, E., and Howard, K. I. (eds.). Patterns of Adolescent Self-image, Jossey-Bass, San Francisco, pp. 19-28.

Baltes, P. B. (1968). Longitudinal and cross-sectional sequences in the study of age and generation effects. Hum. Dev. 11: 145-171.

Baltes, P. B., and Reese, H. W. (1984). The life-span perspective in developmental psychology. In Lamb, M. E., and Bornstein, M. H. (eds.), Developmental Psychology: An Advanced Textbook, Erlbaum, Hillsdale, N.J.

Bock, R. D., Wainer, H., Petersen, A. C., Thissen, D., Murray, J., and Roche, A. (1973). A parameterization for individual human growth curves. Hum. Biol. 45: 63-80

Clausen, J. A. (1975). The social meaning of differential physical and sexual maturation. In Dragastin, S., and Elder, G. (eds.). Adolescence in the Life Cycle, Hemisphere, Washington, D.C.

Crockett, L. J., and Petersen, A. C. (In press). Pubertal status and psychosocial development: Findings from the Early Adolescence Study. In Lerner, R. M., and Foch, T. T. (eds.), Biological-Psychosocial Interactions in Early Adolescence: A Life-Span Perspective, Erlbaum, Hillsdale, N.J.

Crockett, L. J., Losoff, M., and Petersen, A. C. (1984). Perceptions of the peer group and friendship in early adolescence. J. Early Adoles. 4: 155-181.

Crockett, L. J., Schulenberg, J. S., and Petersen, A. C. (1985). A comparison of self-report and objective data in a sample of young adolescents. Manuscript submitted for publication.

Faust, M. S. (1960). Developmental maturity as a determinant in prestige of adolescent girls. Child Dev. 31: 173-184.

Inhelder, B., and Piaget, J. (1958). The Growth of Logical Thinking from Childhood to Adolescence, Basic Books, New York.

Jones, M. C. (1965). Psychological correlates of somatic development. Child Dev. 36: 899-911.

Jones, M. C., and Bayley, N. (1950). Physical maturing among boys as related to behavior J. Educ. Psychol. 41: 129-148.

Jones, M. C., and Mussen, P. H. (1958). Self-conceptions, motivations, and interpersonal attitudes of early and late maturing girls. Child Dev. 29: 491-450.

Kavrell, S. M., and Petersen, A. C. (1984). Patterns of achievement in early adolescence. In Maehr, M. L., and Steinkamp, M. W. (eds.), Advances in Motivation, Vol. 2: Women and Science, JAI Press, Greenwich, Conn., pp. 1-35.

Maccoby, E. E., and Jacklin, C. N. (eds.) (1974). The Psychology of Sex Differences, Stanford University Press, Stanford, Calif.

Mussen, P. H., and Jones, M. C. (1957). Self-conceptions, motivations, and interpersonal attitudes of late and early maturing boys. Child Dev. 28: 243-256.

Neugarten, B. L. (1979). Time, age, and life-cycle. Am. J. Psychiat. 136: 887-894.

Neugarten, B. L., and Datan, N. (1973). Sociological perspectives on the life cycle. In Baltes, P., and Schaie, K. W. (eds.), Life-Span Developmental Psychology: Personality and Socialization, Academic Press, New York. 
Paige, K. E. (1983). A bargaining theory of menarcheal responses in preindustrial cultures. In Brooks-Gunn, J., and Petersen, A. C. (eds.). Girls at Puberty: Biological and Psychosocial Perspectives, Plenum, New York, pp. 301-322.

Peskin, H. (1967). Pubertal onset and ego functioning. J. Abnorm. Psychol. 72: 1-15.

Peskin, H. (1979). Influence of the developmental schedule of puberty on learning and ego development. J. Youth Adoles. 2: 273-290.

Peskin, H., and Livson, M. (1972). Pre- and postpubertal personality and adult psychological functioning. Seminars Psychiat. 4: 343-353.

Petersen, A. C. (1979). Female pubertal development. In Sugar, M. (ed.). Female Adolescent Development, Brunner/Mazel, New York, pp. 23-46.

Petersen, A. C. (1984). The early adolescence study: An overview. J. Early Adoles. 4: 103-106.

Petersen, A. C. (In press a). Pubertal development as a cause of disturbance: Myths, realities, and unanswered questions. J. Genet. Psychol.

Petersen, A. C. (In press b). The nature of biological-psychosocial interactions: The sample case of early adolescence. In Lerner, R. M., and Foch, T. T. (eds.), Biological-Psychosocial Interactions in Early Adolescence: A Life-Span Perspective. Erlbaum, Hillsdale, N.J.

Petersen, A. C., and Taylor, B. (1980). The biological approach to adolescence: Biological change and psychological adaptation. In Adelson, J. (ed.), Handbook of Adolescent Psychology, Wiley, New York.

Petersen, A. C., Crockett, L. J., Richards, M. H., and Boxer, A. M. (1984a). Measuring pubertal status: Reliability and validity of a self-report measure. Manuscript submitted for publication.

Petersen, A. C., Schulenberg, J. E., Abramowitz, R. M., Offer, D., and Jarcho, H. D. (1984b). A Self-Image Questionnaire for Young Adolescents (SIQYA): Reliability and validity studies. J. Youth Adoles. 13:93-111.

Richardson, R. A., Galambos, N. L., Schulenberg, J. E., and Petersen, A. C. (1984). Young adolescents' perceptions of the family environment. J. Early Adoles. 4: 131-153.

Savin-Williams, R. C. (1979). Dominance hierarchies in groups of early adolescents. Child Dev. 50: 923-935.

Schaie, K. W. (1965). A general model for the study of developmental problems. Psychol. Bull. 64: 92-107.

Schulenberg, J. E., Asp, C. E., and Petersen, A. C. (1984). School from the young adolescent's perspective: A descriptive report. J. Early Adoles. 4: 107-130.

Simmons, R. G., Biyth, D. A., and McKinney, K. L. (1983). The social and psychological effects of puberty on white females. In Brooks-Gunn, J., and Petersen, A. C. (eds.), Girls at Puberty: Biological and Psychosocial Perspectives, Plenum, New York, pp. 229-272.

Stolz, H. R., and Stolz, L. M. (eds.) (1944). In Adolescence: Part I, (43rd Yearbook of the National Society for the Study of Education), University of Chicago Press, Chicago.

Thissen, A., Bock, R. D., Wainer, H., and Roche, A. F. (1976). Individual growth in stature: A comparison of four growth studies in the U.S.A. (1976). Hum. Biol. 6: 529-542.

Tobin-Richards, M. H., Boxer, A. M., and Petersen, A. C. (1983). The psychological significance of pubertal change: Sex differences in perceptions of self during early adolescence. In Brooks-Gunn, J., and Petersen, A. C. (eds.), Girls at Puberty: Biological and Psychosocial Perspectives, Plenum, New York, pp. 127-154. 